\title{
Discontinuation of preventive antiepileptic drugs in patients with intracerebral hemorrhage
}

\author{
Yi-Sin Wong ${ }^{1,2}$, Chi-Shun $\mathrm{Wu}^{3}$ and Cheung-Ter $\mathrm{Ong}^{3^{*}}$ (D)
}

\begin{abstract}
Background: The risk factors for seizures in patients with intracerebral hemorrhage (ICH) stroke and the effect of seizure prevention by anticonvulsant are not well understood. Limited studies have investigated the risk of seizure after discontinuing antiepileptic drugs in patients with $\mathrm{ICH}$. This study aimed to investigate the role of valproic acid (VA) for seizure prevention and to access the risk of seizure after anticonvulsant withdrawal in patients with spontaneous ICH.
\end{abstract}

Methods: Between 2013 and 2015, 177 patients with ICH were enrolled in this 3-year retrospective study. Seizures were classified as early seizure (first seizure within 1 week of $\mathrm{ICH}$ ), delayed seizure (first seizure after 1 week), and late seizure (any seizure after 1 week). Binary logistic regression was used to evaluate the relationship between baseline clinical factors and late seizures between study periods. VA was prescribed or discontinued based on the decision of the physician in charge.

Results: Seizures occurred in 24 patients, including early seizure in $6.78 \%(12 / 177)$ of the patients, delayed seizure in $7.27 \%(12 / 165)$ of the patients without early seizure, and late seizure in $9.60 \%(17 / 177)$ of the patients. Most seizures occurred within the first year. Binary logistic regression analysis showed ICH with cortex involvement as the independent risk factor for seizures. VA did not decrease the risk of seizures. Patients with ICH with cortical involvement using anticonvulsants for longer than 3 months did not have a decreased risk of seizures (odds ratio 1.86, 95\% Cl: 0.43-8.05).

Conclusions: Spontaneous ICH with cortex involvement is the risk factor for seizure. Most seizures occurred within 1 year after stroke onset over a 3-year follow up. Discontinuation of antiepileptic drug within 3 months in patients does not increase the risk of seizure.

Keywords: Intracerebral hemorrhage, Stroke, Seizure, Anticonvulsant, Valproic acid, Prophylaxis

\footnotetext{
*Correspondence: ctong98@yahoo.com.tw

${ }^{3}$ Department of Neurology, Ditmanson Medical Foundation Chia-Yi Christian Hospital, 539 Chung-Shao Road, Chia-Yi, Taiwan

Full list of author information is available at the end of the article
}

(c) The Author(s). 2021 Open Access This article is licensed under a Creative Commons Attribution 4.0 International License, which permits use, sharing, adaptation, distribution and reproduction in any medium or format, as long as you give appropriate credit to the original author(s) and the source, provide a link to the Creative Commons licence, and indicate if changes were made. The images or other third party material in this article are included in the article's Creative Commons licence, unless indicated otherwise in a credit line to the material. If material is not included in the article's Creative Commons licence and your intended use is not permitted by statutory regulation or exceeds the permitted use, you will need to obtain permission directly from the copyright holder. To view a copy of this licence, visit http://creativecommons.org/licenses/by/4.0/ The Creative Commons Public Domain Dedication waiver (http://creativecommons.org/publicdomain/zero/1.0/) applies to the data made available in this article, unless otherwise stated in a credit line to the data. 


\section{Background}

Stroke is one of the most common causes of epilepsy. In old patients, more than $50 \%$ of the cases of seizure are related to stroke $[1,2]$. The frequency of seizures after stroke was found to be approximately $4-10 \%$ in patients with ischemic stroke and $4-27 \%$ in patients with hemorrhagic stroke [3-6]. The seizures after stroke include acute symptomatic seizure (early) attack within 1 week after stroke onset and unprovoked (late) seizure onset after 1 week of stroke $[5,7,8]$.

In patients with early seizure, approximately $50 \%$ seizures were found to occur at the onset of intracerebral hemorrhage $(\mathrm{ICH})$ [5]. A previous study reported that patients with stroke who have experienced early seizure have a higher risk of developing late seizure than those who have not [9]. A study by Biffi et al., including 872 patients, found that after 3.9 years of follow up, approximately $50 \%(42 / 86)$ of the patients with early seizure experienced recurrent seizure, and 4.24\% (37/872) experienced late seizure [10].

The effect of early seizure is controversial. A study by Hert et al. reported that in patients with $\mathrm{ICH}$, early seizure does not influence the patient's 6-month outcome $[5,11,12]$. However, another study showed the association between early seizure and poor outcome in a patient with $\mathrm{ICH}$ [13]. The factors that may increase the risk of seizure in patients with $\mathrm{ICH}$ include cortical involvement, intraparenchymal hemorrhage with midline shift, patients with non-neurologic infection, and hemorrhage volume [6, 14-16].

Although the guidelines for the management of $\mathrm{ICH}$ do not recommend the use of prophylactic anticonvulsant treatment for patients without seizures [17], prophylactic anticonvulsant treatment in patients with $\mathrm{ICH}$ is common. A previous study found that prophylactic anticonvulsant for seizure in patients with $\mathrm{ICH}$ can reduce early seizure and improve neurological outcome $[18,19]$.

However, some studies found that prophylactic antiepileptic agents do not reduce the occurrence of seizure. A study by Naidech et al. found that prophylactic levetiracetam in patients with $\mathrm{ICH}$ does not affect seizure and functional outcome but has worse cognitive function and health-related quality of life [20].

The duration for which prophylactic anticonvulsants should be used after ICH is controversial. At present, most of the existing studies have investigated the effect of prophylactic anticonvulsant on patients with $\mathrm{ICH}$, who use phenytoin or levetiracetam. Few studies have investigated the effect of VA. However, there are no studies investigating the duration of prophylactic anticonvulsant in patients with $\mathrm{ICH}$ have been reported. Hence, we performed a study investigating the prophylactic effect of valproic acid (VA) on seizure in patients with $\mathrm{ICH}$.
The aim of the study was to investigate the incidence and associated factors of early and late seizure in patients with $\mathrm{ICH}$. We also investigated whether the discontinuation of the prophylactic anticonvulsant increased the risk of late seizure in patients with $\mathrm{ICH}$.

\section{Methods}

Between Jan 1, 2013 and Dec 31, 2015, 287 patients with intracerebral hemorrhage stroke were admitted to Chia Yi Christian hospital. The hospital is a 1000-bed teaching hospital in central Taiwan. This study was a retrospective study; we reviewed the patients' medical records, including demographic data, vascular risk factors, and the process of care from stroke onset to 3 years after the stroke. Brain computed tomography (CT) was performed based on the electrical medical records.

All consecutive patients with acute neurological symptoms arrived at the emergency department and underwent brain $\mathrm{CT}$, and patients with acute hemorrhagic stroke were included in the study. Patients with $\mathrm{ICH}$ due to trauma, tissue plasminogen activator-related hemorrhage, arteriovenous malformation rupture, subarachnoid hemorrhage (SAH), cerebellar hemorrhage, and brain stem hemorrhage were excluded from the study. All patients were evaluated by a neurosurgeon, and seizures were classified according to the criteria of an international league against epilepsy [21, 22]. Only motor onset focal (with and without impaired awareness) and generalized seizures were included in the study. The definition of seizure was according to that used in previous studies.

Early seizure (ES) was defined as the first seizure occurring within 7 days after stroke. The first seizure occurring beyond 1 week after stroke was defined as delayed seizure (DS). Late seizure was defined as seizure that occurred after 1 week of stroke onset, including patients who had experienced ES and those who had not [10]. The end point of the study was 3 years after stroke onset. If patients had no seizure till 3 years after stroke onset, they were considered to have no seizure. In the emergency department and ward, the patients or their families were inquired about seizures and the onset of stroke.

\section{Demographic characteristics and medical history}

During hospitalization, the following information was collected: 1. Age and gender; 2. Consciousness level (Glasgow coma scale) at admission; 3. Risk factors of stroke; 4. Previous stroke history (infarct, hemorrhage, and undetermined); 5. Previous therapy before stroke. All of the patients were treated for blood pressure control, fluid and nutrition supply, airway management, and surgery according to the guidelines of the American Heart Association [23]. If seizures developed, $400 \mathrm{mg}$ 
VA was administered twice daily, or 3 times a day. The decision of administering anticonvulsant to the patients without seizure was made by the physician in charge. When anticonvulsant was used for patients without seizure, VA was administered at $500 \mathrm{mg}$ every day, $400 \mathrm{mg}$ twice daily or $400 \mathrm{mg}$ three times a day. The timing of discontinuation of the anticonvulsant was decided by the physician.

\section{Radiology assessment}

Brain CT was performed soon after the patients arrived at the emergency department. Follow-up brain CT was performed if necessary, including neurological deficit worsening, seizure attack, consciousness level worsening, or if the patient received surgery. Brain CT images were reviewed in digital image by a neuroradiologist who was blinded to the patients. The hemorrhage volume for $\mathrm{ICH}$ was determined according to $\mathrm{A} \times \mathrm{B} \times \mathrm{C} / 2$ method. $\mathrm{A}$ represents the longitudinal diameter, $\mathrm{B}$ represents the diameter perpendicular to $\mathrm{A}$, and $\mathrm{C}$ represents the number of $10-\mathrm{mm}$ images containing hematoma [6, 24]. CT

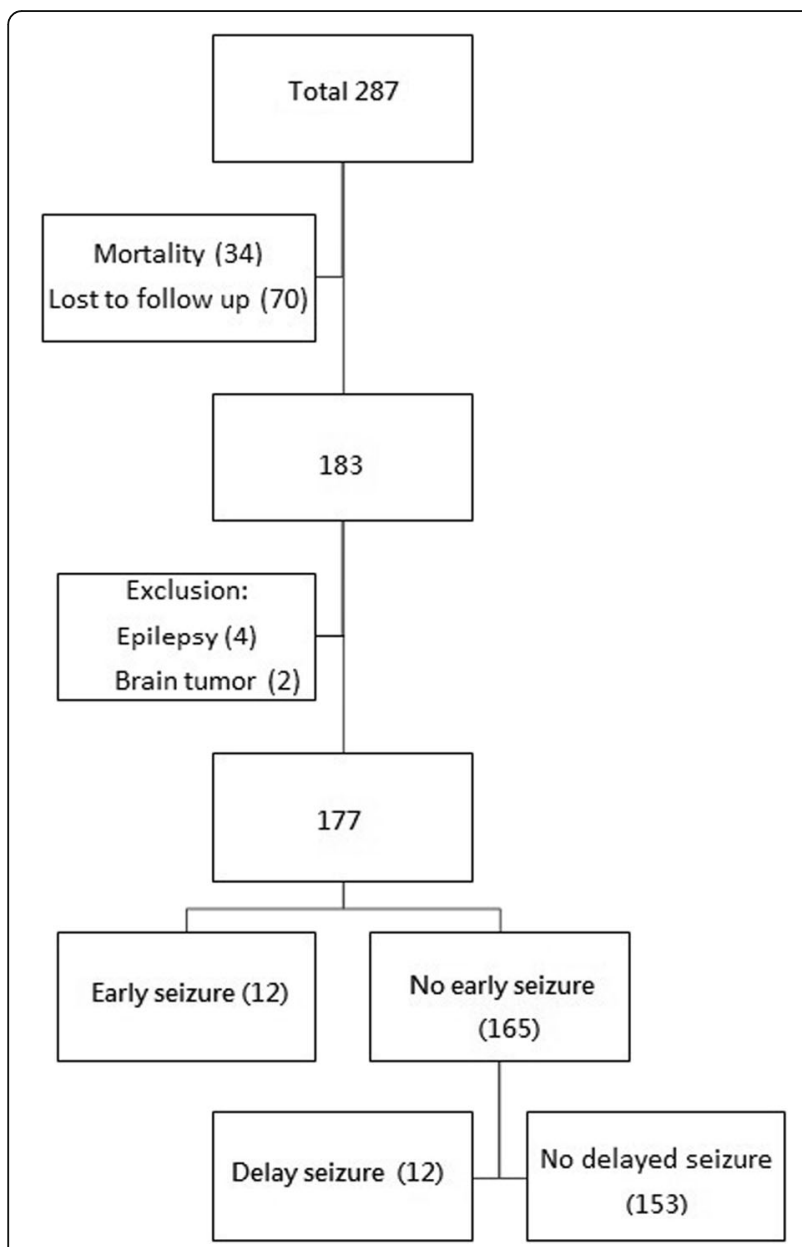

Fig. 1 Flow chart of patient enrollment
Table 1 Characteristics of patients with seizures with intracerebral hemorrhage

\begin{tabular}{|c|c|c|c|c|c|}
\hline & Total (177) & ES $(n=12)$ & $P$ & DS $(n=12)$ & $p$ \\
\hline \multicolumn{6}{|l|}{ Sex } \\
\hline Men & 119 & 10 & & 9 & \\
\hline Women & 58 & 2 & 0.51 & 3 & 0.75 \\
\hline Age & $63.7 \pm 13.6$ & $66.3 \pm 13.5$ & 0.51 & $58.6 \pm 17.9$ & 0.17 \\
\hline \multicolumn{6}{|l|}{ Diabetes } \\
\hline No & 131 & 9 & & 9 & \\
\hline Yes & 46 & 3 & 1 & 3 & 1 \\
\hline \multicolumn{6}{|l|}{ Atrial fibrillation } \\
\hline No & 167 & 12 & & 11 & \\
\hline Yes & 10 & 0 & 1 & 1 & 0.51 \\
\hline \multicolumn{6}{|l|}{ Hypertension } \\
\hline No & 20 & 3 & & 4 & \\
\hline Yes & 157 & 9 & 0.14 & 8 & 0.3 \\
\hline \multicolumn{6}{|l|}{ Stroke history } \\
\hline No & 137 & 9 & & 8 & \\
\hline Infarct & 19 & 2 & 0.75 & 1 & 0.34 \\
\hline Hemorrhage & 21 & 1 & & 3 & \\
\hline \multicolumn{6}{|l|}{ Volume } \\
\hline$<30$ CC & 154 & 7 & & 9 & \\
\hline$\geq 30 \mathrm{CC}$ & 23 & 5 & 0.01 & 3 & 0.19 \\
\hline \multicolumn{6}{|l|}{ Cortex } \\
\hline No & 123 & 3 & & 3 & \\
\hline Yes & 54 & 9 & 0.001 & 9 & 0.001 \\
\hline \multicolumn{6}{|l|}{ Operation } \\
\hline No & 128 & 5 & & 6 & \\
\hline Yes & 49 & 7 & 0.07 & 6 & 0.09 \\
\hline GCS & $11.9 \pm 3.9$ & $10.6 \pm 3.6$ & 0.03 & $12.9 \pm 3.2$ & 0.81 \\
\hline
\end{tabular}

ES early seizure, DS delayed seizure, GCS Glasgow coma scale

image showing a lobar hemorrhage and deep hemorrhage extending to the cortex indicated cortex involvement. Hematoma volume $\geq 30 \mathrm{~cm}^{3}$ (CC) was considered as moderate-to-severe and severe stroke [25]. The study protocol was approved by the Chia Yi Christian hospital's Institutional Review Committee on human research (IRB2020131).

\section{Statistical analysis}

The risk factors for seizure including sex, risk factors of vascular disease and Clinical manifestation were analyzed with the Chi-square or Fisher exact test. Patient age, and coma scale were analyzed using independent $\mathrm{t}$ test. Binary Logistic regression was used to evaluate the relationship between baseline clinical factors and late seizure occurrence during study period. All statistical analyses were conducted using commercially available 


\section{Time to first seizure}

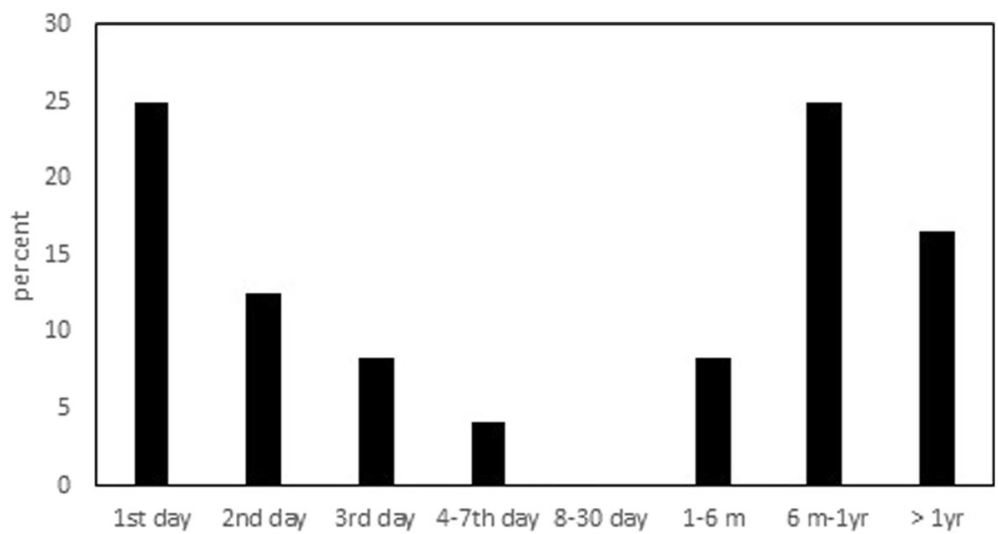

Fig. 2 Delay of occurrence of the first seizure $(n=24)$

software, version 21 of the SPSS system for Windows (version 21.0. IBM Corporation. Somers, NY, USA). Two-sided $P$ values of $<0.05$ were considered statistically significant.

\section{Results}

Between Jan 1, 2013, and Dec 31, 2015, total 287 patients diagnosed with $\mathrm{ICH}$ were admitted to our hospital. After excluding the patients who died within 2 years, were lost to follow-up, or had epilepsy and brain tumor, 177 patients were included in the analysis. The flow chart of patient enrollment and exclusion is shown in Fig. 1. The characteristics of the patients with $\mathrm{ICH}$ are shown in Table 1. Of the 177 patients, 24 patients had seizures within 3 years after stroke onset, 12 had seizure within 1 week, 12 had the first seizure after 1 week of stroke onset, and 153 did not experience any seizures. The timing of seizure attack is shown in Fig. 2. Of the 12 patients who had ES, 50\% (6/12) of the seizures occurred within $24 \mathrm{~h}$ after stroke onset. In the 12 patients who had DS, $66.7 \%(8 / 12)$ of the seizures occurred within 1 year after stroke onset.

Late seizure was found in 17 patients, including 5 recurrent seizures and 12 delayed seizures. Complete blood count and biochemical examination was performed for all of the 17 patients and we ruled out the possibility of seizures related to electrolyte imbalance, infection, alcohol withdrawal or other metabolic factors. Follow-up brain CT was performed for 14 patients and Magnetic Resonance Imaging (MRI) was performed for 1 patient to rule out the possibility of late seizure related to recurrent stroke. Two patients did not undergo follow-up brain CT because no new neurological sign was observed. In the 17 patients with late seizure, no evidence of occurrence of seizure related to recurrent stroke was found.

\section{Factors affecting the use of anticonvulsants}

In the present study, 64 patients were not prescribed anticonvulsants, whereas 113 patients were prescribed anticonvulsants. The factors affecting the prescription of anticonvulsants were hematoma volume $(p<0.01)$, craniotomy $(p<0.01)$ and cortical involvement $(P=0.004)$. Two of the 64 patients $(3.1 \%)$ who did not use anticonvulsants and 15 of the 113 patients (13.3\%) received preventive anticonvulsants had late seizures (Table S1).

Table 2 Factors affecting recurrent seizures in patients with intracerebral hemorrhage with early seizures

\begin{tabular}{|c|c|c|c|c|c|}
\hline & No re-seizure & Re-seizure & $p$ & OR & $95 \% \mathrm{Cl}$ \\
\hline \multicolumn{6}{|l|}{ Anticonvulsant } \\
\hline$\leq 3$ months & 3 & 1 & 0.57 & 1 & $0.21-42.6$ \\
\hline$>3$ months & 4 & 4 & & 4 & \\
\hline \multicolumn{6}{|l|}{ Volumes } \\
\hline$<30$ CC & 4 & 3 & & 1 & \\
\hline$\geq 30 \mathrm{CC}$ & 3 & 2 & 1 & 0.88 & $0.08-9.16$ \\
\hline \multicolumn{6}{|l|}{ Cortex } \\
\hline No & 3 & 0 & & & \\
\hline Yes & 4 & 5 & 0.2 & & \\
\hline \multicolumn{6}{|l|}{ Operation } \\
\hline No & 3 & 2 & & 1 & \\
\hline Yes & 4 & 3 & 0.9 & 0.88 & $0.08-9.16$ \\
\hline \multicolumn{6}{|l|}{ Hypertension } \\
\hline No & 1 & 2 & & 0.3 & \\
\hline Yes & 6 & 3 & 0.52 & 1 & $0.01-3.99$ \\
\hline
\end{tabular}

$O R$ odds ratio, $\mathrm{Cl}$ confidence interval, $R$ e-seizure recurrent seizure 


\section{Factors affecting seizure attack}

Age, sex, Glasgow coma scale, diabetes mellitus, hypertension, atrial fibrillation, stroke history, stroke severity, and operation did not affect the risk of ES. Cortex involvement significantly increases the risk of ES. Hematoma $\geq 30 \mathrm{CC}$ increased risk of early seizures $(P=0.01)$ but not of delayed seizures $(p=0.19)$ (Table 1$)$. Of the 12 patients with ES, no recurrent seizures occurred in those 3 patients who had hemorrhages with no cortex involvement. Five of the $9(55.5 \%)$ patients who had hemorrhage with cortex involvement had recurrent seizures (Table 2).

Sex, age, Glasgow coma scale, diabetes mellitus, hypertension, atrial fibrillation, stroke history, and operation were not significantly different between the patients with DS and those without seizure. In the patients with hemorrhage with cortex involvement, there was a significant increase in the risk of DS $(p=0.006)$. Of the 123 patients without cortex involvement, 2.43\% (3/123) patients had DS, and 16.7\% (9/ 54 ) of the patients with hemorrhage with cortex involvement had DS (Table 1). Under univariate analysis, cortex involvement was found to significantly increase the risk of DS with an odds ratio of 7.7 (95\% CI 1.56-38.5) (Table 3).

The factors affecting late seizure are the same as those affecting early and delayed seizures; the binary logistic regression analysis showed that cortex involvement increases the risk of late seizure with and odds ratio of 22.9 (95\% CI, 3.89-135.4). Patients who used prophylactic anticonvulsant for $>3$ months after stroke did not show a decrease in the risk of late seizures (Table 4).

\section{Effect of discontinuation of prophylactic anticonvulsant} on late seizure

Among the 49 patients who received hematoma evacuation and used prophylactic anticonvulsants, $23.3 \%(6 /$

Table 3 Factors affecting delayed seizures in patients with intracerebral hemorrhage who received antiepileptic medication $(n=$ 113)

\begin{tabular}{|c|c|c|c|c|c|}
\hline & No seizures (103) & Delayed seizures (10) & $P$ & OR & $95 \% \mathrm{Cl}$ \\
\hline \multicolumn{6}{|l|}{ Sex } \\
\hline Women & 33 & 3 & & 1.1 & $0.26-4.52$ \\
\hline Men & 70 & 7 & 0.89 & 1 & \\
\hline Age & $63.1 \pm 12.2$ & $62.2 \pm 17.5$ & 0.81 & & \\
\hline GCS & $11.8 \pm 3.4$ & $13.5 \pm 2.2$ & 0.14 & & \\
\hline \multicolumn{6}{|c|}{ Diabetes mellitus } \\
\hline No & 69 & 9 & & 0.22 & \\
\hline yes & 34 & 1 & 0.17 & 1 & $0.02-1.85$ \\
\hline \multicolumn{6}{|l|}{ Af } \\
\hline No & 99 & 9 & & & \\
\hline Yes & 4 & 1 & 0.37 & 2.75 & $0.27-27.29$ \\
\hline Hypertension & & & & 1 & \\
\hline No & 8 & 4 & & 1 & \\
\hline Yes & 95 & 6 & 0.01 & 0.12 & $0.03-0.54$ \\
\hline \multicolumn{6}{|l|}{ Stroke history } \\
\hline No & 85 & 6 & & & \\
\hline Infarct & 8 & 1 & & & \\
\hline Hemorrhage & 10 & 3 & 0.14 & & \\
\hline \multicolumn{6}{|l|}{ Anticonvulsant } \\
\hline$\leq 3$ month & 87 & 3 & & 12.6 & $2.96-5.42$ \\
\hline$>3$ month & 16 & 7 & 0.01 & 1 & \\
\hline \multicolumn{6}{|l|}{ Cortex } \\
\hline No & 68 & 2 & & 7.7 & \\
\hline Yes & 35 & 8 & 0.006 & 1 & $1.56-38.5$ \\
\hline \multicolumn{6}{|l|}{ Operation } \\
\hline No & 62 & 5 & & 0.66 & \\
\hline Yes & 41 & 5 & 0.53 & 1 & $0.18-2.43$ \\
\hline
\end{tabular}


Table 4 Factors affecting late seizures in patients with intracerebral hemorrhage and who received anticonvulsants (Binary logistic regression)

\begin{tabular}{|c|c|c|c|c|c|}
\hline & No LS & LS & $p$ & OR & $95 \% \mathrm{Cl}$ \\
\hline \multicolumn{6}{|l|}{ Stroke history } \\
\hline No & 81 & 10 & & 1 & \\
\hline Ischemic & 8 & 1 & 0.80 & 0.73 & $0.06-8.64$ \\
\hline Hemorrhage & 9 & 4 & 0.05 & 5.15 & $0.95-27.8$ \\
\hline \multicolumn{6}{|l|}{ Sex } \\
\hline Women & 32 & 4 & & 3.24 & $0.65-16.15$ \\
\hline Men & 66 & 11 & 0.15 & 1 & \\
\hline \multicolumn{6}{|l|}{ Atrial fibrillation } \\
\hline Yes & 4 & 1 & & 0.72 & $0.06-8.23$ \\
\hline No & 94 & 14 & 0.79 & 1 & \\
\hline \multicolumn{6}{|l|}{ Volume } \\
\hline$\geq 30 \mathrm{CC}$ & 17 & 5 & & 0.35 & $0.06-2.11$ \\
\hline$<30 \mathrm{CC}$ & 81 & 10 & 0.25 & 1 & \\
\hline \multicolumn{6}{|l|}{ Operation } \\
\hline Yes & 38 & 8 & & 2.05 & $0.41-10.17$ \\
\hline No & 60 & 7 & 0.37 & 1 & \\
\hline \multicolumn{6}{|l|}{ Cortex } \\
\hline Yes & 30 & 13 & & 22.9 & 3.89-135.4 \\
\hline No & 68 & 2 & 0.001 & 1 & \\
\hline \multicolumn{6}{|l|}{ Anticonvulsants } \\
\hline$>3$ months & 50 & 11 & & 2.05 & $0.50-8.39$ \\
\hline$\leq 3$ months & 48 & 4 & 0.31 & 1 & \\
\hline
\end{tabular}

$L S$ late seizure, $O R$ odds ratio, $C l$ confidence interval

26) of patients who were administrated VA for $>3$ months had late seizures. Three of the 23 (13.0\%) patients who discontinued VA within 3 months after stroke onset had late seizures. The risk of seizure was not significantly different between the patients who discontinued anticonvulsant within 3 months and those who used VA for $>3$ months ( $p=0.47$, 95\% CI: 0.43-9.12). Among patients with hematoma volume $\geq 30$ CC, $20 \%(3 / 15)$ using VA for $>3$ months had late seizure, and 25\% (2/8) who discontinued VA within 3 months after stroke onset had late seizure. The risk of seizure was not significantly different among the patients who did not use VA or discontinued VA within 3 months and those who used VA for $>3$ months ( $p=0.75,95 \%$ CI: 0.09-5.76). Among patients with cortical involvement, $15.4 \%(4 / 26)$ of patients who used VA for $>3$ months had late seizures, and $35.7 \%(10 / 28)$ who discontinued VA within 3 months after stroke onset had late seizures. The risk of late seizure was not significantly different in the patients who discontinued VA within 3 months and the patients who used VA for $>3$ months (OR $=3.05$, 95\% CI: 0.81-11.3) (Table 5).
Table 5 Effect of discontinuation of anticonvulsants on late seizures

\begin{tabular}{|c|c|c|c|c|c|}
\hline & No late seizures & Late seizures & $P$ & OR & $95 \% \mathrm{Cl}$ \\
\hline \multicolumn{6}{|l|}{ Operation } \\
\hline$\leq 3$ months & 20 & 3 & & 2 & $0.43-9.12$ \\
\hline$>3$ months & 20 & 6 & 0.47 & 1 & \\
\hline \multicolumn{6}{|l|}{ Volume $>30 \mathrm{CC}$} \\
\hline$\leq 3$ months & 6 & 2 & & 0.75 & $0.09-5.76$ \\
\hline$>3$ months & 12 & 3 & 1 & 1 & \\
\hline \multicolumn{6}{|l|}{ Cortex } \\
\hline$\leq 3$ months & 22 & 4 & & 3.05 & $0.81-11.3$ \\
\hline$>3$ months & 18 & 10 & 0.12 & 1 & \\
\hline
\end{tabular}

The results showed that discontinuation of VA within 3 months in patients with cortical involvement did not increase the risk of late seizures. Among 43 patients with cortical involvement and who used the prophylactic drug, in $11.5 \%$ (3/26) of patients seizures occurred after they discontinued prophylactic anticonvulsants, and in $58.8 \%(10 / 17)$ of patients seizures occurred during continued use of prophylactic anticonvulsants (Table 6).

\section{Discussion}

In the study, seizure attack was found in $13.6 \%(24 / 177)$ of patients with ICH, ES in $6.7 \%(12 / 177)$, and DS in $6.7 \%(12 / 177)$. ICH with cortical involvement is the only factor affecting early and late seizures. The incidence of seizure reported in our study is similar to those reported by studies by Qian et al. and Woo et al. $[8,14]$. The ES rate was higher than that in the study by Zöllner et al. in Germany, which showed a $4 \%$ incidence rate of ES in patients with $\mathrm{ICH}$. This was lower than that reported by the study by Herdt et al. [5], wherein 14\% (71/522) of their patients had ESs. The difference is suspected to be attributed to most of the ES that occurred at stroke onset and within $24 \mathrm{~h}$ after stroke onset [5]. In the present study, we systemically interviewed the patients and their families about the occurrence of seizure, including seizure attack at stroke onset and before they arrived at the hospital. The study by Herdt et al. found that $>50 \%$ of ESs occur at stroke onset, whereas the study by Zöllner et al. only included seizures during inpatient treatment, which may have underestimated the patient seizure attack before they were brought to the hospital [19]. In our study, $41.7 \%$ (5/12) of patients with early seizure had late seizure within 36 months follow up. The recurrent seizure rate is higher than that reported by Kilpatric et al.; approximately $32 \%$ of their patients had late seizure [9]. The difference is suspected to be related to our study, which had a longer follow-up time. 
Table 6 Characteristics of the 17 patients with late seizures

\begin{tabular}{|c|c|c|c|c|c|}
\hline & Early seizures & Location & Anticonvulsant use & Seizures occurred & Anticonvulsant during seizure \\
\hline 1 & Yes & Lobar & 3 months & 36 months & No \\
\hline 2 & Yes & lobar & 9 months & 33 months & No \\
\hline 3 & Yes & Lobar & 3 years & 11 months & Yes \\
\hline 4 & Yes & Lobar & 2 years & 6 months & Yes \\
\hline 5 & Yes & BG & 3 years & 20 months & Yes \\
\hline 6 & No & BG & No & 7 months & No \\
\hline 7 & No & $B G$ & 1 month & 2 years & No \\
\hline 8 & No & $B G$ & 2 years & 11 months & Yes \\
\hline 9 & No & Lobar & No & 13 months & No \\
\hline 10 & No & Lobar & 0.5 months & 11 months & No \\
\hline 11 & No & Lobar & 4 months & 3 months & Yes \\
\hline 12 & No & Lobar & 3 years & 15 months & Yes \\
\hline 13 & No & Lobar & 2 years & 21 months & Yes \\
\hline 14 & No & Lobar & 2 years & 7 months & Yes \\
\hline 15 & No & lobar & 2 years & 2 months & Yes \\
\hline 16 & No & $B G$ & 2.6 years & 7 months & Yes \\
\hline 17 & No & Lobar & 9 days & 17 months & No \\
\hline
\end{tabular}

BG Basal ganglion

Several studies have investigated early seizure and DS after $\mathrm{ICH}[5,8,10,14]$. In the present study, cortical involvement was found to be an independent factor for early, delayed, and late seizures. Previous studies have reported that with cortical involvement increases the risk of early and late seizures [5, 10, 26, 27]. ES after ICH is suspected to be related to hemorrhage with direct cortical irritation [5].

It is reasonable to consider that hemorrhage volume correlated with high NIHSS (National Institutes of Health Stroke Scale) score and high stroke severity. Nag et al. found that in patients with ICH NIHSS score $\geq 16$, the mean hematoma is $29.03 \mathrm{CC}$. Hematoma volume $\geq$ $30 \mathrm{CC}$ is associated with poor outcome [25, 28]. Our study found that hematoma volume $\geq 30 \mathrm{CC}$ increased the risk of early seizures but not Delayed seizures. This is suspected to be related to hemorrhage with direct cortical irritation. Delayed and late seizures after ICH are suspected to be related to progressive neuronal and white matter damage due to small vessel disease, which amplify the epileptogenic process at the site of hemorrhage [10].

A previous study found young age ( $\leq 60$ years) to be a predictor of seizure after ICH [14]. Our study also found that the patients who had DS were younger than those without DS, but this was not statistically significant.

Recently, most of the studies investigating prophylactic anticonvulsant in patients with ICH used levetiracetam for seizure prevention $[19,29,30]$. Jones et al. found that levetiracetam is as effective as phenytoin in the prevention of post-traumatic ES, but an EEG analysis showed that levetiracetam is associated with an increased seizure tendency [19]. Naidech et al. found that in comparison to levetiracetam, patients with $\mathrm{ICH}$ using phenytoin more frequently experienced in fever and poor outcomes [31]. In our study, our patients used VA for seizure prevention. We did not find an association between anticonvulsant and poor outcome but found that in patients with ICH with cortical involvement, discontinuation of prophylactic anticonvulsant within 3 months did not increase the risk of late seizure.

Although the guidelines for the management of ICH do not recommend that patients without seizures receive prophylactic anticonvulsant treatment [17], antiepileptic drug prophylaxis after $\mathrm{ICH}$ is common [32]. Previous studies found that prophylactic antiepileptic agent use was associated with a worse 3-month functional outcome [31,33]. At present, there is no data available on the duration of prophylactic anticonvulsant in patients with $\mathrm{ICH}$. In the present study, our results showed that the patients with $\mathrm{ICH}$ receiving prophylactic drugs for more than 3 months do not have a decreased risk of seizure compared to the patients who discontinued anticonvulsants within 3 months.

Our study has several limitations. First, the study is a retrospective study; we cannot measure VA serum level, and we did not carry out regular follow-up of electroencephalography (EEG), which may have affected the effects of VA. Whether regular follow-up EEG and adjustment of anticonvulsant dose by drug serum level 
can improve the preventive effects of anticonvulsants need further investigation. Second, the use of anticonvulsant was based on the physician's decision, which may have introduced a bias of a higher stroke severity and larger hematoma volume in the patients receiving anticonvulsants and lower stroke severity and small hematoma volume in the patients not receiving anticonvulsant. In the present study, the stroke severity was significantly higher in the patients who received anticonvulsants than the patients who did not received anticonvulsants $(p<0.01)$ (Table S1). However, we compared the risk of seizures in patients with high seizure risk who used anticonvulsants and discontinued anticonvulsants before and after 3 months of ICH. Third, the study is a single-center study and included a small number of patients.

\section{Conclusion}

Spontaneous ICH with cortical involvement may be a risk factor for early and late seizures. For preventing delayed and late seizures in patients with $\mathrm{ICH}$, discontinuation of anticonvulsants in most patients within 3 months was adequate. Further prospective, randomized, double blind study to investigate the effect and timing of discontinuation of prophylactic anticonvulsant for seizure in patients with ICH may be necessary.

\section{Abbreviations}

Cl: Confidence interval; CT: Computed Tomography; DS: Delay seizure; ES: Early seizure; GCS: Glasgow Coma Scale; ICH: Intracerebral hemorrhage; OR: Odds ratio; SAH: Subarachnoid hemorrhage; VA: Valproic acid

\section{Supplementary Information}

The online version contains supplementary material available at https://doi. org/10.1186/s12883-021-02177-w.

Additional file 1: Table S1. Factors affecting the use of anticonvulsants

\section{Acknowledgements}

The authors would like to thank the stroke teams, persons with stroke and their relatives for contribution in the study.

\section{Authors' contributions}

YW and CO were responsible for the study design. CW was responsible for data collection, performed the analyses and interpreted the results. YW drafted the manuscript. CO and CW reviewed and revised the manuscript. All authors have read and approved the manuscript submitted.

\section{Funding}

None.

\section{Availability of data and materials}

All data used and/or analyzed in the manuscript are available from the corresponding author on reasonable request.

\section{Declarations}

\section{Ethics approval and consent to participate}

The study was approved by the Medical Ethical Committee of the Chia-Yi Christian Hospital (IRB2020131). As this was a retrospective study, the Medical
Ethical Committee of the hospital had approved that the requirement for the informed consent was waived.

\section{Consent for publication}

Not applicable.

\section{Competing interests}

All authors declare no competing interests.

\section{Author details}

'Department of Family Medicine, Ditmanson Medical Foundation Chia-Yi Christian Hospital, Chia-Yi, Taiwan. ${ }^{2}$ Department of Nursing, Min-Hwei Junior College of Health Care Management, Tainan, Taiwan. ${ }^{3}$ Department of Neurology, Ditmanson Medical Foundation Chia-Yi Christian Hospital, 539 Chung-Shao Road, Chia-Yi, Taiwan.

Received: 27 October 2020 Accepted: 29 March 2021

Published online: 07 April 2021

\section{References}

1. Hauser WA, Annegers JF, Kurland LT. Incidence of epilepsy and unprovoked seizures in Rochester, Minnesota: 1935-1984. Epilepsia. 1993;34(3):453-68. https://doi.org/10.1111/j.1528-1157.1993.tb02586.x.

2. Li X, Breteler MM, de Bruyne MC, Meinardi H, Hauser WA, Hofman A, et al. Vascular determinants of epilepsy: the Rotterdam Study. Epilepsia. 1997; 38(11):1216-20. https://doi.org/10.1111/j.1528-1157.1997.tb01219.x.

3. Bladin CF, Alexandrov AV, Bellavance A, Bornstein N, Chambers B, Cote R, et al. Seizures after stroke: prospective multicenter study. Arch Neurol. 2000; 57(11):1617-22. https://doi.org/10.1001/archneur.57.11.1617.

4. Silverman IE, Restrepo L, Mathews GC. Poststroke seizures. Arch Neurol. 2002;59(2):195-201. https://doi.org/10.1001/archneur.59.2.195.

5. De Herdt VM, Dumont F, Henon HM, Derambure P, Vonck KM, Leys D, et al. Early seizures in intracerebral hemorrhage: incidence, associated factors, and outcome. Neurology. 2011;77(20):1794-800. https://doi.org/10.1212/WNL. ob013e31823648a6.

6. Vespa PM, O'phelan K, Shah M, Mirabelli J, Starkman S, Kidwell C, et al. Acute seizures after intracerebral hemorrhage: a factor in progressive midline shift and outcome. Neurology. 2003;60(9):1441-6. https://doi.org/1 0.1212/01.WNL.0000063316.47591.B4.

7. Haapaniemi E, Strbian D, Rossi C, Putaala J, Sipi T, Mustanoja S, et al. The CAVE score for predicting late seizures after intracerebral hemorrhage. Stroke. 2014;45(7):1971-6. https://doi.org/10.1161/STROKEAHA.114.004686.

8. Qian C, Lopponen P, Tetri S, Huhtakangas J, Juvela S, Turtiainen HM, et al. Immediate, early and late seizures after primary intracerebral hemorrhage. Epilepsy Res. 2014;108(4):732-9. https://doi.org/10.1016/j.eplepsyres.2014.02. 020.

9. Kilpatrick CJ, Davis SM, Hopper UL, Rossiter SC. Early seizures after acute stroke. Risk of late seizures. Arch Neurol. 1992;49(5):509-11. https://doi.org/1 0.1001/archneur.1992.00530290097017.

10. Biffi A, Rattani A, Anderson CD, Ayres AM, Gurol EM, Greenberg SM, et al. Delayed seizures after intracerebral haemorrhage. Brain. 2016;139(Pt 10): 2694-705. https://doi.org/10.1093/brain/aww199.

11. Fung C, Balmer M, Murek M, Z'Graggen WJ, Abu-lsa J, Oadoba C, et al. Impact of early-onset seizures on grading and outcome in patients with subarachnoid hemorrhage. J Neurosurg. 2015;122(2):408-13. https://doi. org/10.3171/2014.10.JNS14163.

12. Mullen MT, Kasner SE, Messe SR. Seizures do not increase in-hospital mortality after intracerebral hemorrhage in the nationwide inpatient sample. Neurocrit Care. 2013;19(1):19-24. https://doi.org/10.1007/s12028012-9791-0

13. Li Z, Zhao X, Wang Y, Wang C, Liu L, Shao X, et al. Association between seizures and outcomes among intracerebral hemorrhage patients: the China National Stroke Registry. J Stroke Cerebrovasc Dis. 2015;24(2):455-64. https://doi.org/10.1016/j.jstrokecerebrovasdis.2014.09.021.

14. Woo K-M, Yang S-Y, Cho K-T. Seizures after spontaneous intracerebral hemorrhage. J Korean Neurosurg Soc. 2012;52(4):312-9. https://doi.org/1 0.3340/jkns.2012.52.4.312

15. Zollner JP, Konczalla J, Stein M, Roth C, Krakow K, Kaps M, et al. Acute symptomatic seizures in intracerebral and subarachnoid hemorrhage: a population study of 19,331 patients. Epilepsy Res. 2020;161:106286. https:// doi.org/10.1016/j.eplepsyres.2020.106286. 
16. Yang TM, Lin WC, Chang WN, Ho JT, Wang HC, Tsai NW, et al. Predictors and outcome of seizures after spontaneous intracerebral hemorrhage. Clinical article. J Neurosurg. 2009;111(1):87-93. https://doi.org/10.3171/2 009.2.JNS081622.

17. Hemphill JC III, Greenberg SM, Anderson CS, Becker K, Bendok BR, Cushman $M$, et al. Guidelines for the management of spontaneous intracerebral hemorrhage: a guideline for healthcare professionals from the American Heart Association/American Stroke Association. Stroke. 2015;46(7):2032-60. https://doi.org/10.1161/STR.0000000000000069.

18. Gilad R, Boaz M, Dabby R, Sadeh M, Lampl Y. Are post intracerebral hemorrhage seizures prevented by anti-epileptic treatment? Epilepsy Res. 2011;95(3):227-31. https://doi.org/10.1016/j.eplepsyres.2011.04.002.

19. Jones KE, Puccio AM, Harshman KJ, Falcione B, Benedict N, Jankowitz BT, et al. Levetiracetam versus phenytoin for seizure prophylaxis in severe traumatic brain injury. Neurosurg Focus. 2008;25(4):E3. https://doi.org/10.31 71/FOC.2008.25.10.E3.

20. Naidech AM, Beaumont J, Muldoon K, Liotta EM, Maas MB, Potts MB, et al. Prophylactic seizure medication and health-related quality of life after Intracerebral hemorrhage. Crit Care Med. 2018:46(9):1480-5. https://doi. org/10.1097/CCM.0000000000003272.

21. Fisher RS, Cross JH, French JA, Higurashi N, Hirsch E, Jansen FE, et al. Operational classification of seizure types by the international league against epilepsy: position paper of the ILAE commission for classification and terminology. Epilepsia. 2017;58(4):522-30. https://doi.org/10.1111/epi.13 670.

22. Fisher RS, Cross JH, D'Souza C, French JA, Haut SR, Higurashi N, et al. Instruction manual for the ILAE 2017 operational classification of seizure types. Epilepsia. 2017;58(4):531-42. https://doi.org/10.1111/epi.13671.

23. Morgenstern LB, Hemphill JCIII, Anderson CM, Becker K, Broderick JP, Connolly ESJ, et al. Guidelines for the management of spontaneous intracerebral hemorrhage: a guideline for healthcare professionals from the American Heart Association/American Stroke Association. Stroke. 2010;41(9): 2108-29. https://doi.org/10.1161/STR.0b013e3181ec611b.

24. Broderick JP, Brott TG, Duldner JE, Tomsick T, Huster GM. Volume of Intracerebral hemorrhage: a powerful and easy-to-use predictor of 30-day mortality. Stroke. 1993;24(7):987-93. https://doi.org/10.1161/01.STR.24.7.987.

25. Nag C, Das K, Ghosh M, Khandakar MR. Prediction of clinical outcome in acute hemorrhagic stroke from a single CT scan on admission. N Am J Med Sci. 2012;4(10):463-7. https://doi.org/10.4103/1947-2714.101986.

26. Beghi E, D'Alessandro R, Beretta S, Consoli D, Crespi V, Delaj L, et al. Incidence and predictors of acute symptomatic seizures after stroke. Neurology. 2011; 77(20):1785-93. https://doi.org/10.1212NNL.0b013e3182364878.

27. Gilmore E, Choi HA, Hirsch $\perp$, Claassen J. Seizures and CNS hemorrhage: spontaneous intracerebral and aneurysmal subarachnoid hemorrhage. Neurologist. 2010;16(3):165-75. https//doi.org/10.1097/NRL.0b013e3181c7cd0b.

28. Albdert M, Lin JH, Chen YW, Kogen E, Twyman K, Deshmukh S, et al. Initial stroke severity is a crucial predictor for hemorrhagic stroke-and ischemic stroke-related mortality. J Am Coll Cardiol. 2018;71(11):A1900.

29. Panczykowski DM, Pease MM, Zhao YB, Weiner G, Ares W, Crago E, et al. Prophylactic antiepileptics and seizure incidence following subarachnoid hemorrhage: a propensity score- matched analysis. Stroke. 2016;47(7):175460. https://doi.org/10.1161/STROKEAHA.116.013766.

30. Naidech AM, Beaumont J, Jahromi B, Prabhakaran S, Kho A, Holl JL. Evolving use of seizure medications after intracerebral hemorrhage: a multicenter study. Neurology. 2017;88(1):52-6. https://doi.org/10.1212/WNL. 0000000000003461.

31. Naidech AM, Garg RK, Liebling S, Levasseur K, Macken MP, Shuele SU, et al. Anticonvulsant use and outcomes after intracerebral hemorrhage. Stroke. 2009:40(12):3810-5. https://doi.org/10.1161/STROKEAHA.109.559948.

32. Sheth KN, Martini SR, Moomaw CJ, Koch S, Elkind MSV, Sung G, et al. Prophylactic antiepileptic drug use and outcome in the ethnic/racial variations of intracerebral hemorrhage study. Stroke. 2015;46(12):3532-5. https://doi.org/10.1161/STROKEAHA.115.010875.

33. Messé SR, Sansing LH, Cucchiara BL, Herman ST, Lyden PD, Kasner SE. Prophylactic antiepileptic drug use is associated with poor outcome following ICH. Neurocrit Care. 2009;11(1):38-44. https://doi.org/10.1007/s12 028-009-9207-y.

\section{Publisher's Note}

Springer Nature remains neutral with regard to jurisdictional claims in published maps and institutional affiliations.

Ready to submit your research? Choose BMC and benefit from:

- fast, convenient online submission

- thorough peer review by experienced researchers in your field

- rapid publication on acceptance

- support for research data, including large and complex data types

- gold Open Access which fosters wider collaboration and increased citations

- maximum visibility for your research: over $100 \mathrm{M}$ website views per year

At BMC, research is always in progress.

Learn more biomedcentral.com/submissions 